\title{
Gobernadores sin contrapesos. El control de los medios de comunicación locales como estudio de caso en Querétaro
}

\author{
Governors unchecked. Control of local \\ communication media as a case study in Queretaro
}

doi: http://dx.doi.org/10.32870/

espiral.v23i67.5693

\section{Resumen}

En este artículo se discute la conceptualización de "autoritarismo subnacional" y se ejemplifica con el caso de estudio del estado de Querétaro, mostrando cómo el gobernador de dicha entidad domina al resto de poderes e instituciones públicas locales, con énfasis en su control sobre los medios de comunicación. Se utiliza una recolección de estudios similares de todo el país para observar cómo el caso de Querétaro encuentra réplicas en otras entidades federativas. Para el estudio de caso se realizaron dos series de entrevistas a periodistas y exfuncionarios públicos. Se concluye que en México la democracia se ha instalado en el nivel federal, sin embargo, esto no ha sucedido exitosamente en el plano subnacional, y que los mandatarios estatales han logrado ganar poder en la esfera nacional, pero han perdido contrapesos en el nivel local durante el periodo de la transición política.

Palabras clave: Gobiernos subnacionales, medios de comunicación locales, gobernadores, democracia, autoritarismo.

\author{
Germán Espino Sánchez*
}

\begin{abstract}
In this article the conceptualization of "subnational authoritarianism" is discussed and exemplified by a case study. The state of Queretaro serves to show how the governor dominates the rest of powers and local public institutions, with focus on how the governor controls the local media. A collection of similar studies around the country shows that the state of Queretaro is an example of how the governors control the local media. The conclusion is that democracy has been installed on the federal level, however, this has not happened successfully at the subnational level. This research shows how the governors have managed to gain power at the national level but have lost counterweights at the local level during the period of political transition. For the case study two series of interviews with journalists and former officials were performed.
\end{abstract}

Keywords: Subnational government, local mass media, governors, democracy, authoritarianism.

\footnotetext{
- Profesor-Investigador de la Facultad de Ciencias Políticas y Sociales de la Universidad Autónoma de Querétaro. herman@uaq.mx

Fecha de recepción: 15 de junio de 2015. Fecha de aceptación: 05 de mayo de 2016.
} 


\section{Introducción}

Los principales estudios sobre Gobiernos subnacionales en América Latina muestran que en el nivel de las entidades federativas se están desarrollando regímenes que tienen características de democracia, pero también de autoritarismo; a pesar de que esto parece una contradicción para las teorías tradicionales, existen muchas investigaciones profundas que lo sustentan (Gibson, 2006; Campos, 2012; Balán, 2013). A este tipo de Gobiernos subnacionales se les ha llamado "regímenes híbridos", "semidemocracias" y "autoritarismos subnacionales", este último el concepto más difundido.

Las investigaciones sobre este tema no han llegado a una conclusión satisfactoria porque subsisten muchas contradicciones conceptuales, entre ellas destacan: 1) es difícil afirmar que un Gobierno subnacional puede ser autoritario en el contexto de una democracia nacional; 2) en las entidades se realizan elecciones libres y a veces competitivas, pero, a menudo, estas elecciones están controladas por un partido, por lo que este partido gana muy frecuentemente, o siempre, y a veces con victorias aplastantes que rondan el $80 \%$ en los casos más extremos (por ejemplo, esto ha sucedido en Argentina -Balán, 2013-); 3) los gobernadores de estas entidades, a pesar de ser electos democráticamente, no desarrollan una poliarquía como forma de gobierno, sino que someten al resto de poderes públicos y, en ocasiones, transgreden el marco institucional de manera impune, lo cual los acerca más a un Gobierno de corte autoritario que a uno democrático.

Hay que aclarar que en el caso de cinco estados de la república mexicana donde no se ha registrado alternancia es difícil hablar de elecciones competitivas porque estos registran más de ochenta y cinco años con Gobiernos emanados del Partido Revolucionario Institucional (PRI); no 
obstante, los reportes hablan de que en estas entidades sí se celebran elecciones libres.

Los estados donde siempre ha gobernado el PRI desde su constitución, en 1929, son Colima, Coahuila, Hidalgo, el Estado de México y Campeche. Los investigadores latinoamericanos coinciden en que este tipo de regímenes caería en la clasificación de sistemas de partido hegemónico (Sartori, 1987), es decir, regímenes no democráticos, debido a que tienen una larga historia de elecciones controladas por un partido y, por ello, poco competitivas (Balán, 2013).

En términos formales, habría que admitir que la regla general es que los gobernadores en México surgen de procesos electorales legales y de elecciones más o menos libres. El problema de fondo es que en la mayoría de los estados de la república aún se vive una concentración de poder en la figura del Ejecutivo local. Este "gran actor" subordina al resto de poderes del estado: legislatura, Poder Judicial, medios de comunicación y grupos empresariales, etc. (Ruelas y Dupuy, 2013; Gutiérrez, 2013). Este parece ser el patrón dominante en la mayoría de los estados del país: un gobernador que concentra el poder y domina el espacio público. En este artículo se citarán estudios de caso sobre la mayoría de estados de la república que confirman esta hipótesis.

Con respecto a esta paradoja, un régimen autoritario subnacional alojado en una democracia nacional, hay que insistir en los escasos referentes teóricos sobre las democracias subnacionales. Las teorías de la transición usualmente refieren a procesos nacionales, por lo que los problemas de los Gobiernos subnacionales son espacios poco explorados, a veces incompatibles con las teorías de la transición tradicionales (Gibson, 2006; Balán, 2013). Los principales autores que escriben sobre el tema apuntan que, aparentemente, las transiciones democráticas nacionales han fortalecido los autoritarismos subnacionales. 
Los Gobiernos subnacionales de México parecen interesantes como objeto de estudio, además, por otro motivo: diversos autores narran cómo la democratización fue un proceso que en cierta forma comenzó en los estados y luego arribó al centro del país (Woldemberg, 2002; Campos, 2012). Es decir, durante el proceso de transición, los primeros bastiones del autoritarismo que cayeron fueron algunas gubernaturas de los estados: Baja California, en 1989; Guanajuato, en 1991; Chihuahua, en 1992, etc. Sin embargo, diversos reportes describen una regresión autoritaria en los estados en la primera década del siglo XXI, mientras que en el nivel nacional en este mismo periodo hay claros signos de que se estableció una democracia más o menos funcional (Woldemberg, 2002; Casar, 2010; Loaeza, 2010; Aguayo, 2014).

En este artículo se analiza una muestra de esta paradójica mezcla de democracia y autoritarismo subnacional. Se hace énfasis en mostrar cómo en el nivel nacional se ha desarrollado un sistema plural de medios, mientras que en el nivel subnacional sobrevive un sistema de medios sometidos al gobernador. Se analiza cómo las coberturas electorales en los medios nacionales se desarrollan con una equidad significativa, mientras que, en el nivel estatal, las coberturas electorales de los medios locales muestran un sesgo muy pronunciado a favor del partido gobernante. Se muestra, con estudios de análisis de contenido y entrevistas, cómo los gobernadores controlan los medios regionales, tal como se hacía en los tiempos del autoritarismo priista; para ello, se toma como estudio de caso el estado de Querétaro.

\section{Antecedentes}

$\mathrm{Al}$ sistema político que se estableció después de la Revolución mexicana (entre 1927 y 1989) se le ha clasificado como un régimen autoritario (Meyer, 1995; Linz, 2009) y, en

\section{4}


ocasiones, como un régimen de partido hegemónico (Sartori, 1987). En este artículo se adopta la definición de Linz (2009), pues, como ya se ha documentado históricamente, durante este periodo se realizaban elecciones que en realidad no eran competitivas (Meyer, 1995). Por ello, el régimen era autoritario en el sentido que dice Linz:

Son sistemas políticos con pluralismo político limitado, no responsable, carentes de una ideología elaborada y directora, pero con mentalidades características, carentes de una movilización política extensa e intensa, excepto en algunos momentos de su desarrollo, y en los que un líder, o a veces un pequeño grupo, ejerce el poder dentro de límites formalmente mal definidos pero en realidad predecibles (Linz, 2009, p. 255).

Con el comienzo de los gobiernos de alternancia en varios estados, comenzó el periodo de transición democrática. Esta se conceptualiza como el intervalo entre un régimen autoritario y uno democrático (O’Donnell y Schmitter, 1994, p. 19).

La mayor parte de politólogos de México, quizá los más importantes, consideran que la transición democrática ya terminó y advierten que ya hay una democracia instalada en el nivel federal, aunque siguen existiendo contradicciones y problemas de todo tipo (Casar, 2010; Loaeza, 2010; Woldemberg, 2002; Aguayo, 2014).

En este sentido, algunos autores critican el estado de esta democracia. Por ejemplo, Meyer habla de una democracia autoritaria. Incluso, John Ackerman (2015) es quizá el politólogo más importante que no considera que en México se haya establecido una democracia. Y aunque, como se ha señalado antes, los politólogos hablen de una democracia ya instalada, el principal problema ahora sería, quizá, la calidad de esta democracia (Diamond y Morlino, 2005).

Resulta difícil abordar la discusión sobre lo que es una democracia en un artículo, de manera que en el presente 
se utiliza la "definición mínima de democracia" que sugiere Norberto Bobbio (en González y Quesada, 1988, p. 40): “es el conjunto de reglas o procedimientos que permiten tomar decisiones colectivas mediante el debate libre y el cálculo de la mayoría”.

Según Bobbio, las características de una democracia son: 1) todos los ciudadanos deben tener iguales derechos políticos, entre los que sobresale el derecho al voto; 2) el voto de todos debe ser igual, es decir debe tener el mismo peso; 3) los ciudadanos deben ser libres para votar; 4) deben contar, además, con alternativas reales para votar; 5) el Gobierno debe ser electo por el principio de mayoría numérica, aunque este revista diferentes formas; y 6) las decisiones de la mayoría no deben limitar los derechos de la minoría (González y Quesada, 1988, p. 40).

A esta definición, Sartori agrega que "el verdadero fundamento de todo Gobierno democrático es la opinión de los gobernados" (Sartori, 1993, p. 55), y que este elemento de la democracia (la opinión pública) se materializa en los procesos electorales.

Sartori advierte que la opinión pública influye decisivamente en los políticos y sus programas, pues cuando estos no atienden a la opinión pública esta no vuelve a brindarles su apoyo; de esta manera es que los políticos, tarde o temprano, rinden cuentas a la opinión pública (Sartori, 1993, p. 73). Para lograr este objetivo, se precisa que la opinión pública sea autónoma, que verdaderamente sea del público, que nazca en el seno de los que la expresan. Por ello, se dice "opinión pública" no sólo porque se origina en un "público", sino también porque esta opinión versa sobre lo público, sobre lo político, sobre el bien común, lo cual basta para que se constituya como uno de los pilares de la democracia (Sartori, 1993, p. 57).

Según este autor, para que la opinión pública cumpla su función en la democracia se presuponen tres condiciones: 
libertad de pensamiento, libertad de expresión y policentrismo (Sartori, 1993, p. 64).

La libertad de pensamiento consiste en que el individuo puede recurrir a todas las fuentes de pensamiento y que es libre para controlar la información que recibe en forma escrita y oral.

Por su parte, la libertad de expresión exige que el ciudadano sea libre para exteriorizar lo que piensa, lo cual supone una atmósfera de seguridad, es decir, que no se reprima, sino que se fomente la expresión de las ideas.

Finalmente, la típica estructura de los medios de comunicación de una democracia consiste en una multiplicidad de centros, un policentrismo, que es particularmente contrastante con el monocentrismo de totalitarismos, autoritarismos y dictaduras (Sartori, 1993, p. 65).

Esta es la concepción tradicional de democracia que estaría en conflicto con los autoritarismos subnacionales, donde no hay poderes que hagan contrapeso al gobernador y, por tanto, no hay policentrismo. Además, como los medios de comunicación locales están controlados por el gobernador, la opinión pública dificilmente puede ser libre.

\section{Presidencialismo y corporativismo en los estados}

La mayoría de las tradiciones teóricas que estudian el Estado posrevolucionario mexicano plantean que el régimen se estructura sobre cuatro relaciones fundamentales: 1) el presidencialismo como centro ordenador de toda la política nacional; 2) el corporativismo como instrumento operativo de la élite gobernante; 3) el partido de Estado como la institución que ordenaba el acceso al poder en la clase política; 4) un sistema electoral no pluralista (González, 1976; Córdova, 1972; Woldemberg, 2002).

De esta estructura del régimen autoritario cabe destacar dos elementos para la presente discusión: por una parte, el 
corporativismo que dio forma al sistema de medios nacional y estatal; por la otra, el presidencialismo, porque, desde aquella época, en los estados el gobernador se convertía en el centro de poder, a semejanza del presidente en el nivel nacional.

Con respecto al corporativismo, hay que recordar que casi todos los grupos sociales fueron cooptados e integrados en los sectores del PRI. Esta práctica corporativa se convertiría en política de Estado. A partir de entonces, el Gobierno crearía y fomentaría instituciones que integrarían a todos los sectores sociales en virtuales aparatos del Estado (González, 1976; Córdova, 1972). Estas relaciones corporativas son importantes para el presente caso de estudio porque representan el modelo de las relaciones que se establecieron entre los gobernantes y los medios de comunicación.

Durante un régimen autoritario, los principales medios de comunicación llegan a constituirse como grupos de presión integrados al sistema autoritario. Los grupos de interés que disfrutan de un acceso privilegiado en el proceso de decisión son calificados como insiders, o ya establecidos, frente a los outsiders, o no establecidos (Grant, 1995). Esta conceptualización ayuda a comprender las relaciones del Gobierno con los medios que eran oficialistas y a diferenciarlos de los medios independientes.

Grant (1995) formaliza la distinción en función de las estrategias y los modos de actuación de los propios grupos; establece que los insiders tienen como objetivo establecer un proceso consultivo con el Gobierno antes que este adopte una decisión definitiva sobre un tema que afecta a sus proyectos.

Sin embargo, existe una gran variedad de grupos insiders (Maloney, Jordan y Mc Lauchlin, 1994), desde los que tienen una gran influencia en el Gobierno, hasta los que prácticamente no logran una influencia visible. Entre los primeros, podrían ubicarse los grandes consorcios mediáticos nacionales (Televisa y TV Azteca) que, hasta la fecha, han mantenido una gran influencia en el Gobierno federal y los 
estatales. En cambio, entre los grupos de presión que casi no tienen influencia en el Gobierno se encontrarían los medios locales, los cuales no pueden acotar a los gobernadores.

En este contexto, hay que remarcar que los gobernadores establecen relaciones clientelares con los grupos de poder en los estados. En todos los reportes (Campos, 2012; Ruelas y Dupuy, 2013; González, 2015) se remarca que los gobernadores, más que reprimir, se dedican a comprar las voluntades de los medios. Para ello, ofrecen recursos de muy diverso tipo. En este sentido, son sistemas clientelares más que represivos.

El clientelismo es un modelo de organización social en el cual el acceso a los recursos sociales está controlado por patrocinadores y permitido a los "clientes" a cambio de prebendas económicas y privilegios políticos (Hallin y Mancini, 2008).

En esta forma de organización social, las reglas formales tienen menos importancia que las relaciones personales. En un sistema clientelar, el compromiso con intereses particulares es más fuerte y la noción del "bien común" es más débil (Hallin y Mancini, 2008).

En la época del régimen autoritario, este sistema clientelar fue desarrollado por el PRI con las corporaciones como la Confederación de Trabajadores de México (CTM), la Confederación Nacional Campesina (CNC), la Confederación Nacional de Organizaciones Populares (CNOP), etc., para cooptar y controlar a todos los sectores de la sociedad. Diversos reportes muestran que este sistema clientelar ha persistido en las entidades de la federación (Ruelas y Dupuy, 2013; Campos, 2012; González, 2015).

\section{Las relaciones de los presidentes con los gobernadores}

En la época del régimen autoritario, el presidente ejercía una gran influencia sobre los gobernadores, pero no era 
una relación de sometimiento. Los gobernadores tenían autonomía en algunos procesos locales y, a cambio, cedían otros procesos a las decisiones del presidente. El presidente no podía extender su poder a todos los rincones del país, por lo que necesitaba a los gobernadores como aliados y representantes (Hernández, 2008).

Desde esta época, los gobernadores se convirtieron en el centro de poder en los estados, a semejanza del presidente de la república. Algunos autores denuncian que, en ocasiones, los gobernadores se manejaban en sus estados con un exceso de fuerza muy superior al que se veía en el nivel nacional en la Presidencia (Campos, 2012).

Cuando la población se rebelaba a un gobernador excesivamente autoritario, o cuando este se oponía frontalmente a los dictados de la federación, el mandatario local podía ser removido por el presidente de la república. Por ejemplo, el presidente Carlos Salinas removió a diecisiete gobernadores (Weldon, 1997, pp. 253-254). Esta controversial forma de control de los excesos de los gobernadores y de exceso de poder del presidente de la república se perdió cuando Vicente Fox ganó la Presidencia nacional, en el 2000.

Desde los años ochenta, el presidente Miguel de la Madrid comenzó un proceso de descentralización de los servicios de salud y de la educación hacia los estados. Con ello, se inició la descentralización del poder presidencial y la consolidación de los gobernadores.

La descentralización cobró fuerza con el presidente Ernesto Zedillo, quien implementó medidas que fortalecieron el poder de los gobernadores, entre otras: 1) eliminó el Programa Nacional de Solidaridad, y a cambio creó un ramo presupuestal que dependía de los indicadores de desarrollo de los estados y no de la asignación discrecional del Gobierno federal; 2) los titulares de las delegaciones federales en los estados comenzaron a ser negociados con los gobernadores y a trabajar para estos; 3) permitió que 
los candidatos a gobernadores fueran electos en elecciones primarias, las cuales eran controladas por los mandatarios estatales (Hernández, 2008).

Durante la presidencia de Vicente Fox, los gobernadores aprendieron a imponer sus condiciones al Gobierno federal. En 2002, el presidente Vicente Fox propuso recortes presupuestales a los estados, pero estos se organizaron en la Conferencia Nacional de Gobernadores (Conago) y ordenaron a sus diputados del Congreso Federal que, en vez de recortes, autorizara incrementos presupuestales a los estados. Lograron que el 50\% de los ingresos excedentes por la venta del petróleo se entregara a los gobiernos estatales (Hernández, 2008).

Durante el sexenio de Fox (2000-2006), así como en el de Felipe Calderón (2006-2012), los gobernadores se convirtieron en los líderes de los partidos nacionales. Ni las estructuras partidarias del PRI ni las del Partido de la Revolución Democrática (PRD) tuvieron la capacidad de enfrentar el poder de los gobernadores (Campos, 2012; Hernández, 2008). Como las elecciones tienen un carácter regional y los gobernadores son la pieza central de estos procesos, entonces eran ellos quienes podían comprometerse a hacer ganar a los candidatos que ellos mismos escogían.

Los gobernadores vieron a la Conago como una oportunidad de desarrollar más su influencia en una época en la que el PRI había perdido la Presidencia de la república (Hernández, 2009a). Los gobernadores sabían que las administraciones de Vicente Fox y Felipe Calderón necesitarían a los diputados, senadores y gobernadores del PRI para negociar incluso cuestiones básicas como los presupuestos de egresos de cada año (Hernández, 2009a). De esta manera, la acumulación de poder en manos de los gobernadores, en la primera década del siglo XXI, ha sido uno de los cambios más significativos del sistema político mexicano. 
Esta gran influencia nacional que desarrollaron los gobernantes promovió que en sus respectivos estados los mandatarios lograran una concentración de poder aún mayor que la que tenían durante el régimen autoritario. Por ejemplo, en el caso de Querétaro, durante la primera década del siglo XXI se pudo observar que el gobernador panista Francisco Garrido disputó, en repetidas ocasiones, al presidente Calderón el control del Partido Acción Nacional (PAN) en el estado; en la mayoría de estas ocasiones, este gobernador terminó imponiéndose al presidente (Espino, 2012).

En la primera década del siglo XXI, los gobernadores procuraban que en las elecciones locales se consolidara una mayoría legislativa de su partido, o negociaban con la oposición el control de la legislatura (Hernández, 2013). Con esta mayoría legislativa les era posible controlar la elección de los magistrados del Poder Judicial, la elección de consejeros electorales, la elección del presidente de la Comisión Estatal de Derechos Humanos y la elección del presidente de la Comisión Estatal de Acceso a la Información. Además, claramente, los gobernadores dominaban a su partido en el nivel local, e incluso designaban a su sucesor durante esta primera década (Hernández, 2008).

En ese contexto, es obvio que el gobernador en turno lograría controlar a los principales actores del espacio público en su estado, entre los que destacaban los grupos empresariales y los medios de comunicación locales (Morales, 2012). Estos últimos dependían económicamente de la publicidad que pagaba el Gobierno del estado, así como de la información oficial que generaban las dependencias estatales (Ruelas y Dupuy, 2013; Gutiérrez, 2013).

El mandatario estatal, a fin de cuentas, lograba cooptar a la mayoría de los medios de comunicación para que funcionaran dentro de la estrategia de propaganda gubernamental (Espino, 2012). En el caso del estado de Querétaro, se puede citar, por ejemplo, que, entre el año 2004 y el 
2008, el gobierno de Francisco Garrido Patrón gastó casi USD 50000000 en publicidad oficial (Fortanell y Cabrera, 2009).

Incluso, otros gobernadores, como Enrique Peña Nieto (quien fuera gobernador del Estado de México entre 2005 y 2011), se involucraron en escándalos nacionales por los excesivos presupuestos destinados a medios nacionales y locales (Villamil, 2009; García, 2012).

Esta excesiva concentración de poder permitió que los gobernantes tomaran decisiones arbitrarias, e incluso que, en los casos más escandalosos, muchos actos ilegales quedaran impunes (Casar, 2015).

Entre las decisiones que mayores escándalos produjeron en la primera década del siglo XXI se encuentran: 1) las excesivas deudas que contrajeron estados y municipios; 2) las flagrantes violaciones a los derechos humanos; y 3) los casos de enriquecimiento inexplicable y actos de corrupción de gobernadores, así como de su gabinete o de su familia.

Entre los exgobernadores exhibidos en este tipo de escándalos destacan Humberto Moreira, Andrés Granier, Mario Marín, Fausto Vallejo, Luis Armando Reynoso y Eugenio Hernández (Martínez, 2013).

Como aclara Hernández (2009a), desde el sexenio del presidente Zedillo hasta el de Felipe Calderón, ni los presidentes ni la Legislatura federal, ni siquiera la Suprema Corte, han podido destituir a un gobernador que incurra en flagrantes actos de corrupción, ni siquiera en los casos más sórdidos como los de Mario Marín, en Puebla, o Ulises Ruiz, en Oaxaca (Hernández, 2009a). 
Cuadro 1. Estados con mayor deuda adquirida entre 2008 y 2012 (millones de pesos)*

\begin{tabular}{lcc} 
Estado & Deuda total & Deuda adquirida (2008-2012) \\
Coahuila & 22289.6 & 20984.9 \\
Veracruz & 19429.6 & 12718.6 \\
Nuevo León & 24432.8 & 11288.6 \\
Jalisco & 16308.4 & 7299.2 \\
Chihuahua & 11517.7 & 6906.5 \\
Quintana Roo & 8330.9 & 6313.6 \\
Tamaulipas & 6785.6 & 5682.4 \\
Michoacán & 10059.5 & 5113.7 \\
Chiapas & 9214.2 & 4040 \\
Baja California & 7803 & 3091.1 \\
Zacatecas & 3101.7 & 2633.3 \\
Nayarit & 3603.6 & 2476.8 \\
Morelos & 1842.4 & 1486.6 \\
Puebla & 5916 & 1258.2 \\
\hline * Entre 2008 y junio de 2012, la deuda subnacional creció en 95 000 \\
millones de pesos. Catorce entidades, que adquirieron pasivos por más \\
de mil millones en esos años, concentraron casi el 96\% de ese monto. \\
\hline
\end{tabular}

Fuente: Martínez (2013).

\section{Estrategia metodológica}

Para el presente trabajo, se utilizó una metodología de estudio de caso como lo exponen Martínez (2006), Barrio del Castillo, et al. (2006) y Stake (2005). Para construir un caso, es común que se recurra a técnicas cualitativas y cuantitativas (Barrio del Castillo, et al., 2006).

Los estudios de caso tratan de explicar un proceso social particular, abordarlo desde sus diferentes aristas, problematizarlo para comprenderlo en toda su complejidad. Para lograr la comprensión de este fenómeno social, se recoge una gran cantidad de información, desde diferentes ángulos, con diferentes técnicas (entrevistas, investigación documental, observación, etc.), hasta lograr familiaridad con el caso, 
de manera que el investigador se convierte en un verdadero experto de su objeto de estudio. Se busca triangular y contrastar los datos con diferentes fuentes para obtener explicaciones confiables.

Para comprobar las hipótesis de esta investigación, se recopilaron estudios empíricos como análisis de contenido, estudios de rating, encuestas, estudios de audiencias, etc.

Se realizaron dos series de entrevistas a periodistas y a exfuncionarios del Gobierno estatal de Querétaro. Una primera serie, con los reporteros, buscó conocer la situación laboral: contratos, salarios, prestaciones, etc., de los trabajadores de los medios. La segunda serie de entrevistas se realizó a directivos de medios y a exfuncionarios gubernamentales que tenían la responsabilidad de llevar las relaciones públicas con ellos.

Además, se recopilaron estudios sobre la relación entre los medios y los gobernadores de los otros veintidós estados de la república mexicana. Estos estudios corroboran el presupuesto de la presente investigación: Querétaro es un ejemplo de cómo los gobernadores controlan a los medios de comunicación locales.

\section{Sistema de medios nacional (2006-20I2)}

A continuación, se muestra cómo se configura esta paradoja de la instalación de un espacio público plural nacional y, en contraposición, otro de control de los medios en el nivel local; para ello, se usa el estudio de medios realizado y recolectado, así como la serie de entrevistas que se realizó a periodistas y exfuncionarios gubernamentales. Se compara en una línea del tiempo la evolución del escenario nacional y el local.

Para mostrar las diferencias entre el subsistema de medios nacional y los subsistemas locales, se contrastan los resultados de los análisis de contenido nacionales con 
los análisis de contenido del estado de Querétaro. Con esta comparación se muestra cómo los medios locales siguen las tendencias de la época del autoritarismo, mientras que en el escenario de los medios nacionales se ha desarrollado una mayor pluralidad.

Los resultados de análisis de contenido que estudian las coberturas que los medios nacionales brindan a los procesos federales muestran la pluralidad que existe en el panorama nacional de los medios en las primeras décadas del siglo XXI. Existen muchos autores que han explorado y explicado esta circunstancia (Riva Palacio, 2004; Trejo, 2001; Hughes, 2006; Lawson, 2002). Para mostrarlo de manera sencilla, se elaboró un cuadro comparativo de los análisis de contenido sobre las coberturas de campaña en los principales productos noticiosos del país en las últimas dos décadas.

En el Cuadro 2, se puede apreciar cómo los medios nacionales -básicamente Televisa y TV Azteca- brindaban coberturas excesivamente sesgadas a favor del PRI en 1988 y 1994; esto cambió a partir del 2000, cuando la equidad en las coberturas a los diferentes partidos se convirtió en la norma hasta la última medición, que se recolectó en 2012. En esta primera década del siglo XXI ya se otorgaban espacios casi iguales a los tres grandes partidos: PRI, PAN y PRD.

De esta manera, en el panorama de los medios nacionales, se puede hablar de una pluralidad externa y de una pluralidad interna (Hallin y Mancini, 2008; Hughes, 2006). La pluralidad externa refiere a que los diferentes medios se compensan entre sí, pues existen medios de líneas editoriales con diferentes tendencias ideológicas. Por ejemplo, si bien existen medios afines a la derecha, como el periódico Excélsior, la revista Contenido, la revista Letras Libres y los noticiarios de TV Azteca, etc., también existen medios de clara filiación de izquierda, como el periódico La Jornada, la revista Proceso y los noticiarios de Carmen Aristegui. Incluso, se podría decir que muchos medios están más cerca 
del centro en el espectro ideológico, como los periódicos Reforma y El Universal (Hughes, 2006).

Cuadro 2. Cobertura de las campañas de los partidos en los dos principales noticiarios de TV y sus respectivos resultados en las urnas $(1988, * 1994,2000,2006,2009$ y $2012 * *)$

\begin{tabular}{rrrrrrr} 
Año & \multicolumn{2}{c}{ PRI } & \multicolumn{2}{c}{ PRD } & \multicolumn{2}{c}{ PAN } \\
& TV & Votación & \multicolumn{1}{c}{ TV } & Votación & \multicolumn{1}{c}{ TV } & Votación \\
1988 & $91.71 \%$ & $50 \%$ & $3.94 \%$ & $31 \%$ & $3.48 \%$ & $17 \%$ \\
1994 & $32.01 \%$ & $48.7 \%$ & $19.3 \%$ & $16.6 \%$ & $16.69 \%$ & $25.9 \%$ \\
2000 & $28.12 \%$ & $36.11 \%$ & $27.4 \%$ & $16.64 \%$ & $30.4 \%$ & $42.52 \%$ \\
2006 & $22 \%$ & $22.23 \%$ & $21 \%$ & $35.33 \%$ & $19 \%$ & $35.89 \%$ \\
2009 & $21.78 \%$ & $37.09 \%$ & $16.9 \%$ & $12.2 \%$ & $21.0 \%$ & $27.98 \%$ \\
2012 & $30.8 \%$ & $38.20 \%$ & $26.1 \%$ & $31.6 \%$ & $26.5 \%$ & $25.39 \%$ \\
\hline
\end{tabular}

* Para el caso de 1988, se toma la votación obtenida por el Frente Democrático Nacional (FDN), del cual emergería el PRD. En cuanto a coaliciones partidistas a considerar, en el 2000 el PRD contendió en coalición con otros partidos bajo la fórmula "Alianza por México", y, en 2006, en la "Coalición por el bien de todos". Por su parte, el PRI, en 2006, compitió en la "Alianza por México", y, en 2012, en alianza con el PVEM bajo la fórmula "Compromiso por México". En cuanto al PAN, en 2000 lo hizo bajo la fórmula "Alianza por el cambio".

** El análisis de contenido del IFE en 2006, 2009 y 2012 no desglosó los resultados de la cobertura de acuerdo a los diferentes programas de la TV, por lo cual los resultados que se presentan en este cuadro se refieren a la cobertura de todos los programas de TV y radio del país monitoreados por el IFE.

Fuente: elaboración propia con base en los resultados electorales publicados por el IFE (2012) y el análisis de contenido de Academia Mexicana de Derechos Humanos (1994 y 2000) y Trejo (2001).

La pluralidad interna refiere a que muchos medios, sobre todo los más importantes, congregan a periodistas y analistas de diferentes tendencias ideológicas, lo que lleva a que estos medios desarrollen una cobertura noticiosa más plural. Esto es especialmente significativo en los noticiarios y periódicos más exitosos. Se debe hacer referencia en este 
sentido, por ejemplo, a El Noticiero, del periodista Joaquín López Dóriga, en Televisa. En este noticiero tradicionalmente concurren como editorialistas los intelectuales más importantes del país, tanto de izquierda como de derecha.

Hay que matizar que esta pluralidad interna y externa también tiene muchas limitaciones. La principal crítica que se realiza al sistema de medios nacional refiere a que existen medios con un gran impacto, como las televisoras, y medios con menor impacto, como los periódicos. Otros estudios de medios denuncian que las televisoras tradicionalmente se asocian al grupo gobernante, mientras que los periódicos tienen mayor independencia del poder político (Márquez Ramírez, 2012; Espino y Mendoza, 2015).

El problema de fondo es que las televisoras, con una cobertura de tipo oficialista, en tiempos no electorales son las que tienen una mayor influencia; según la Encuesta Nacional de Cultura Política, para el 76.6\% de los mexicanos la principal fuente de información es la televisión; sólo el 15\% dice leer periódicos cotidianamente (Secretaría de Gobernación, 2012).

\section{Panorama de los medios locales de Querétaro}

En el caso de Querétaro, no se ha podido elaborar un cuadro que globalmente muestre el sesgo de los noticiarios, pues los diferentes análisis de contenido que se han realizado en el periodo 1997-2012 se han elaborado con diferentes metodologías.

Por ello, se exponen de manera sintética los resultados de los estudios de los años 1997, 2003 y 2009, los cuales corresponden a las campañas por la gubernatura, la elección más importante en el estado. También se muestra el análisis de contenido realizado en 2012 , el cual sólo refiere a elecciones por las alcaldías, no por la gubernatura. 
Para monitorear el proceso electoral de 1997, la empresa Síntesis Informativa del Bajío realizó un análisis de contenido de los periódicos locales Noticias y Diario de Querétaro, así como de los semanarios Nuevo Amanecer y Nuevo Milenio.

Los resultados de este análisis de contenido contrastan con la tendencia nacional de pluralidad. En las campañas para gobernador de Querétaro en 1997, el candidato del PRI, Fernando Ortiz Arana, obtuvo el 82.4\% de los espacios televisivos dedicados a candidatos a la gubernatura, como se puede ver en el Cuadro 3 (Síntesis informativa del Bajío, 1997).

En las campañas para la gubernatura de 2003, los medios privilegiaron las campañas del PRI y PAN, y marginaron al resto de los partidos. Quizá esto se origina porque los medios locales acostumbran vender no sólo la publicidad, sino también la información que difunden (Espinosa, 2003), al grado que algunas notas de periódicos denuncian casos de venta de la cobertura de las campañas (Hernández, 2009b). Además, uno de los periodistas entrevistados para el estudio de caso confirmó que los periódicos vendieron la cobertura de los candidatos en las campañas señaladas (entrevista personal, 2013b).

Otro de los periodistas entrevistados para el estudio de caso informó que en 2003 los medios locales creían que en las elecciones triunfaría el candidato priista (entrevista personal, 2013b), de manera que suponían que cuando este fuera gobernador les ayudaría a recuperar la inversión que habían hecho en la campaña. Una prueba de la privilegiada cobertura al candidato del PRI en dicha campaña es el análisis de contenido que muestra el Cuadro 4.

A pesar del apoyo de los medios locales en 2003, el candidato del PRI perdió la elección. En este sentido, los medios obtuvieron su tercera "derrota" al hilo: primero en 1997, luego en el 2000 y, finalmente, en el 2003. La mayoría de 


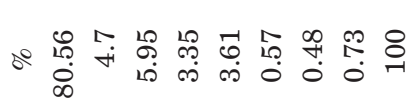

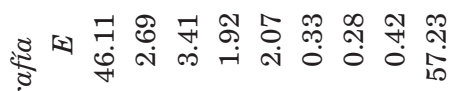

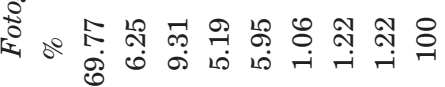

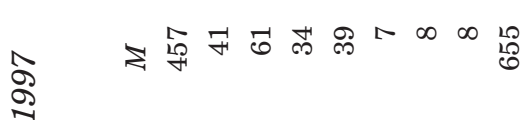

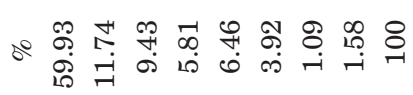

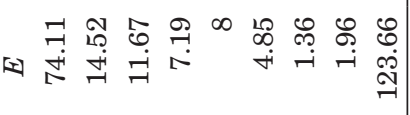

$$
\begin{aligned}
& \text { ぷ }
\end{aligned}
$$

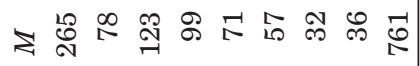

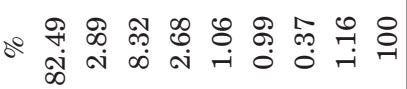

$$
\begin{aligned}
& \text { 节 } \\
& \text { 蒂 }
\end{aligned}
$$

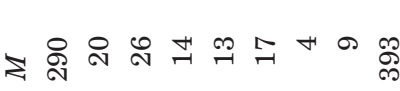

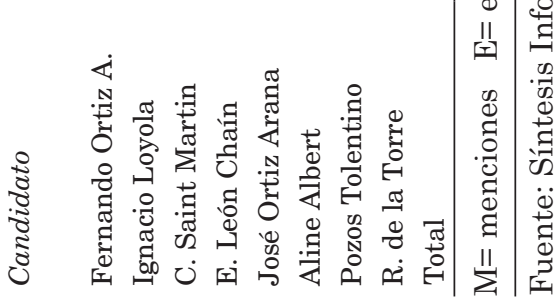


medios volvió a apostar por el PRI y perdió con este partido (Espino, 2003; entrevista personal, 2013b).

Cuadro 4. Análisis de contenido de la cobertura de los diarios a las campañas de 2003

Espacios asignados por Espacios asignados por Diario de Querétaro Noticias, diario de la mañana

\begin{tabular}{lrrrrrrrrr} 
& $A P T^{*}$ & $P A N^{*}$ & $A S C^{*}$ & $A P T^{*}$ & $P A N^{*}$ & $A S C^{*}$ & $A P T^{*}$ & $P A N^{*}$ & $A S C^{*}$ \\
Notas & 53 & 3 & 14 & 114 & 49 & 7 & 94 & 72 & 27 \\
Fotos & 75 & 1 & 10 & 126 & 34 & 12 & 157 & 116 & 42 \\
$\mathrm{~cm}^{2}$ & 30053 & 1182 & 3976 & 50421 & 15207 & 3290 & 34853 & 28108 & 8887 \\
\hline * Las siglas corresponden a los siguientes partidos: APT, Alianza Para & \\
& Todos (PRI-PVEM); PAN, Partido Acción Nacional; ASC, Alianza con la \\
\\
Sociedad Civil (PRD-PMP).
\end{tabular}

Fuente: Cueto y Espinosa (2003).

En el periodo de las campañas para la gubernatura de 2009, los medios locales ya tenían claro que el PAN llevaba una racha ganadora. Por tanto, estaban convencidos de que el candidato del PAN para la gubernatura ganaría la elección. En esta campaña, la mayoría de medios locales apoyó al candidato del PAN de manera contundente (Rodríguez, et al., 2010), pero este perdió.

El análisis de contenido de 2009 evaluó la cobertura de los dos periódicos locales de mayor tiraje y de uno de los noticiarios locales de radio con mayor audiencia (Rodríguez, et al., 2010).

El medio más equitativo fue el noticiario Para Continuar, que brindó solamente 5\% más espacio al PAN que al PRI. En cambio, el medio más parcial resultó ser el Diario de Querétaro, que otorgó casi $74 \%$ de sus espacios al candidato del partido en el Gobierno (Cuadro 5) y apenas $23 \%$ de espacio al candidato de oposición. Como se puede apreciar, se repitieron las tendencias tradicionales: los medios brindaron 
una excesiva cobertura al candidato oficial, aunque ahora este era el candidato del PAN.

Cuadro 5. Espacio otorgado a los candidatos del PRI, PAN y PRD en campañas para gobernador en 2009

\begin{tabular}{lccc} 
Medio de comunicación & $\begin{array}{c}\text { Manuel } \\
\text { González } \\
\text { Valle (PAN) }\end{array}$ & $\begin{array}{c}\text { José Calzada } \\
\text { Rovirosa (PRI) }\end{array}$ & $\begin{array}{c}\text { José Carlos } \\
\text { Borbolla } \\
\text { (PRD) }\end{array}$ \\
Diario de Querétaro & $73.97 \%$ & $23.50 \%$ & $2.53 \%$ \\
Noticias & $61.43 \%$ & $37.54 \%$ & $1.03 \%$ \\
Para continuar & $50.66 \%$ & $46.02 \%$ & $3.31 \%$ \\
Porcentaje promedio & $62.03 \%$ & $35.53 \%$ & $2.29 \%$ \\
\hline
\end{tabular}

Fuente: Rodríguez, et al. (2010).

En esta elección se repitió la paradoja de 1997, pero en sentido contrario. Es decir, en 1997 los medios de comunicación "apostaron" todo al candidato del partido en el Gobierno (PRI) y perdieron la "apuesta"; en 2009, nuevamente los periódicos "apostaron" todo al candidato del partido gobernante (ahora el PAN) y, nuevamente, "perdieron" la apuesta.

En 2012, se analizó la cobertura que brindaron los tres periódicos locales más importantes del estado a las campañas de candidatos y partidos (Espino y Mendoza, 2015). En dicho año, en Querétaro, se llevaron a cabo las elecciones para ayuntamientos y Congreso local, junto con las elecciones federales por la Presidencia y por el Congreso federal.

El análisis de contenido muestra que los periódicos privilegiaron al PRI y a sus candidatos, no sólo en lo cuantitativo, sino, sobre todo, en lo cualitativo (Espino y Mendoza, 2015). Esta cobertura sesgada hacia el PRI se originó en que el gobernador de ese momento tenía su afiliación en este partido, además del hecho de que todas las encuestas daban un gran margen de ventaja a Enrique Peña Nieto, candidato priista para la Presidencia de la república. Debe destacarse que en dicha ocasión los medios locales aposta- 
ron a los candidatos locales y federales del PRI, los cuales resultaron ganadores en las elecciones.

El candidato a la Presidencia por el PRI (Enrique Peña Nieto) fue el candidato que obtuvo más menciones y más espacios en los medios Diario de Querétaro y AM, en tanto que Noticias brindó una mayor cobertura a los dos principales candidatos para la alcaldía capitalina (Roberto Loyola, del PRI, y Armando Rivera, del PAN): ambos recibieron un trato similar en la cantidad de notas y espacios en este periódico. No obstante, Roberto Loyola obtuvo una cobertura con un sesgo más positivo que su contrincante: logró cincuenta y cuatro menciones con juicios de valor positivos y una sola con juicio negativo, mientras que Armando Rivera obtuvo solamente veintiséis juicios de valor positivos y siete negativos.

Tanto en el Diario de Querétaro como en el Noticias se privilegió a los candidatos del PRI de una manera muy significativa en las variables de juicios de valor. En cambio, en el $A M$ se privilegió a los candidatos del PRI, obsequiándoles más menciones, aunque estas fueron neutras (Espino y Mendoza, 2015).

En términos generales, puede considerarse que las coberturas sesgadas del Diario... y de Noticias en favor del PRI (en 2012) tuvieron su base en los convenios de publicidad que se celebraron antes y durante la campaña.

Es decir, los Gobiernos de signo priista realizan importantes contratos de publicidad con estas empresas periodísticas, pero, además, los candidatos del PRI suscriben contratos de publicidad para que sus campañas reciban un trato preferencial en la información.

Esto ha sido ampliamente confirmado por los entrevistados en el estudio de caso realizado (entrevista personal, 2013b; entrevista personal, 2014a); además, diversos periodistas locales han denunciado públicamente este tipo de 
contratos en diversas campañas (Lazos, 1997; Espinosa, 2003; Hernández, 2009b).

Cuadro 6. Unidades de análisis que se brindaron a los candidatos en 2012 (por partidos)

\begin{tabular}{cccccc}
\multicolumn{2}{c}{$\begin{array}{c}\text { Diario de Querétaro } \\
\text { Cantidad de }\end{array}$} & \multicolumn{2}{c}{ Noticias } & \multicolumn{2}{c}{$A M$} \\
Cantidad de & $\%$ & Cantidad & $\%$ \\
unidades & \multicolumn{3}{c}{$\begin{array}{c}\text { lnidades } \\
\text { de unidades }\end{array}$} \\
276 & 39.88 & 495 & 42.70 & 308 & 39.38 \\
197 & 28.46 & 409 & 35.28 & 244 & 31.20 \\
102 & 14.73 & 109 & 9.40 & 132 & 16.87 \\
\hline
\end{tabular}

Fuente: elaboración propia con base en datos obtenidos de observación directa.

Cuadro 7. Unidades de análisis que se brindaron a los principales candidatos en 2012

Enrique Peña Nieto

Josefina Vázquez Mota

Andrés Manuel López Obrador

Roberto Loyola

Armando Rivera

Francisco Domínguez

Otros candidatos locales PRI

Otros candidatos locales PAN
Diario de Querétaro

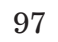

64

67

53

45

33

49

17
Noticias AM

$71 \quad 147$

$56 \quad 111$

$63 \quad 109$

$98 \quad 59$

$102 \quad 60$

$29 \quad 19$

$155 \quad 18$

$138 \quad 17$

Fuente: elaboración propia con base en datos obtenidos de observación directa.

Cuadro 8. Espacios dedicados a los candidatos

por partidos en 2012

\begin{tabular}{lccc} 
& Diario de Querétaro & Noticias & $A M$ \\
PRI & 45 planas & 98 planas & 36.60 \\
PAN & 21 planas & 76 planas & 29.50 \\
PRD & 18 planas & 17 planas & 17.24 \\
\hline
\end{tabular}

Fuente: elaboración propia con base en datos obtenidos de observación directa. 
Por otra parte, el análisis de contenido realizado no logró explicar la gran campaña negativa que los periódicos y medios locales emprendieron contra el candidato Armando Rivera. A este candidato se le acusó de tener cuentas bancarias con millones de dólares en el extranjero, de traficar con migrantes indocumentados, de tener amantes, etc. (Espino y Mendoza, 2015).

Hasta donde se pudo investigar, los periódicos basaron sus acusaciones en rumores sin fundamento. Estas acusaciones se multiplicaron en las primeras planas de los periódicos locales. Aunque el candidato acusado aportó pruebas de que estas denuncias eran falsas, los periódicos desdeñaron las evidencias y mantuvieron la campaña negativa (Espino y Mendoza, 2015).

Como se puede ver, en la campaña de 2012 los medios asociados al Gobierno se desataron de los controles legales y políticos que los vinculaban a una frágil democracia; el contubernio de estos medios con los Gobiernos y con los candidatos priistas muestra a profundidad el carácter autoritario del periodismo local.

Deben aclararse los riesgos de este contubernio: si los medios pueden atentar contra importantes candidatos que tienen un gran peso político, económico y de convocatoria pública (como el exalcalde Armando Rivera), ¿qué no podrían hacer contra ciudadanos comunes y corrientes? Esto pone en entredicho las libertades civiles de la sociedad local, sin las cuales un estado difícilmente se puede considerar "democrático".

\section{Patrones en la relación entre gobernadores y medios locales}

Las relaciones que establecieron los gobernadores con los medios locales en la mayor parte de los estados del país en la primera década del siglo XXI se estudiaron durante cinco 
años. Para este estudio, se recopilaron reportes de investigación que muestran cómo se establecen las relaciones entre estos dos sectores. En términos generales, puede asegurarse que existen dos patrones fundamentales en estas relaciones:

1. Un gobernador controla al resto de poderes locales $\mathrm{y}$, en consecuencia, también al espacio público y, por añadidura, a los medios locales (Ruelas y Dupuy, 2013; Gutiérrez, 2013; Espino y Mendoza, 2015). Este es el patrón más común.

2. En algunos estados se desarrolla un periodismo independiente y crítico de la clase política y de los poderes fácticos; este periodismo independiente tiene sustento en grupos muy importantes de la sociedad civil, los cuales pueden acotar el poder del gobernador (Smith, et al., 2008). Estos estados constituyen una excepción a la regla del gobernador sin contrapesos, la cual se puede observar en la mayor parte de los estados de la república.

Sobre el primer caso, hay que advertir que a un gobernador le resulta fácil controlar a los medios de comunicación estatales cuando domina a todos los poderes locales. Sin embargo, hay que remarcar que el sometimiento es un juego a dos bandas: por una parte, el Ejecutivo quiere someter a los medios y, por la otra, a los dueños de los medios les interesa negociar su línea editorial a cambio de jugosos contratos de publicidad gubernamental y, en ocasiones, de significativos privilegios económicos y políticos (Ruelas y Dupuy, 2013; entrevista personal, 2013a; entrevista personal, 2014b).

En este patrón también es importante considerar el nivel de precariedad que los periodistas sufren en casi todo el país. Los diversos reportes muestran que los reporteros suelen estar muy mal pagados e, incluso, en algunas ocasiones, trabajan sin sueldo. Esto los obliga a buscar un subsidio 
económico con el Gobierno estatal. Este, a su vez, suele destinar grandes recursos para comprar todas las voces públicas, en especial las de los medios.

En este sentido, también es importante señalar que la mayoría de los medios y periodistas locales no suelen ser muy profesionales: no buscan comercializar sus páginas con las empresas privadas ni tampoco subsistir a partir de su circulación, sino que se conforman con vivir a expensas de la publicidad oficial (Ruelas y Dupuy, 2013; González, 2015; Espino y Mendoza, 2015).

En México, el sometimiento de los poderes locales y de los medios de comunicación es una vieja tradición que proviene del régimen autoritario, pero esto también es un efecto de cómo, a nivel nacional, los presidentes de la república, desde 1994 hasta 2012, cedieron poder a otros actores de una manera descontrolada.

En este contexto, los gobernadores llenaron algunos vacíos de poder que dejaron los presidentes Ernesto Zedillo, Vicente Fox y Felipe Calderón. Los gobernadores acumularon poder en vez de cederlo a otras instituciones locales o nacionales más trasparentes, como hubiera sido conveniente para lograr mejores democracias en el nivel estatal (Hernández, 2009a; Campos, 2012).

En el caso de los cinco estados que no han registrado alternancia desde la época de la Revolución, la permanencia prolongada del PRI en el poder sí se convierte en un factor importante para que el gobernador someta a los medios locales. En estos estados es común encontrar el patrón del gobernante que somete a los poderes locales y a los medios; se pueden mencionar en esta circunstancia estados como Coahuila, Campeche, Hidalgo, Estado de México y Colima.

Desde una perspectiva teórica, estos patrones se explicarían porque los sistemas mediáticos locales se estructuran de acuerdo a los sistemas políticos que adoptan las sociedades (Mancini y Hallin, 2008). Por ello es comprensible que 
en estados con regímenes locales autoritarios o semiautoritarios se encuentren medios cooptados por la estrategia comunicacional del gobernador.

Sin embargo, hay que advertir que si bien el patrón más generalizado es el del gobernador que controla los medios, también existen muchas variaciones dentro de este patrón, dependiendo del gobernante y de los sistemas de medios locales. Como en la virtud, en el vicio también hay muchos grados.

Si se intentara una clasificación, se podría hablar de un primer grupo de entidades en las que el gobernador ejerce un dominio casi absoluto sobre los medios locales. Entre estos estados se ubican Querétaro (Espino, 2012), Hidalgo (Hernández y Hernández, 2011), Estado de México (Santillán Buelna, 2007), Nayarit (Orozco Murillo, 2007), Veracruz (Ortega Polanco, 2013; Del Palacio, 2015), Michoacán (González, 2015), Tamaulipas (Gutiérrez, 2013) y Coahuila (Lemini, 2015).

En segundo lugar, existe otro grupo de estados en los que el gobernador controla a los medios locales que tienen grandes audiencias, pero en estos casos algún o algunos medios medianamente importantes se escapan del control del Gobierno estatal, ya sea porque el medio trata de identificarse con la tradición de periodismo independiente y crítico, o porque el medio se asocia a una ideología distinta a la del gobernador.

Sin embargo, estos medios locales "disidentes" son excepcionales y no logran promover un espacio público plural porque este, generalmente, está cooptado por la estrategia comunicacional del gobernador. Esto es lo que se ha visto en los reportes de estudios sobre los casos de Sinaloa (Rodelo Amezcua, 2008), Sonora (Ruelas y Dupuy, 2013), Oaxaca (Ruelas y Dupuy, 2013) y Puebla (Ruelas y Dupuy, 2013), entre otros. 
En el otro extremo del espectro, en tercer lugar, hay estados donde existen medios consolidados y con una gran influencia, lo cual hace pensar que el gobernador no controla el espacio público. Este es el caso de algunos de los estados más prósperos del país, entre los que destacan Nuevo León (Smith, et al., 2008), Guanajuato (Ruelas y Dupuy, 2013) y Jalisco (Hernández, 2010). En estos estados suelen florecer medios asociados a la gran tradición del periodismo independiente y crítico, ese tipo de periodismo que considera a los medios como un "watch dog" de la democracia, un tipo de periodismo crítico de los excesos de los gobernantes y de los poderes fácticos. El común denominador de estos estados parece ser una tradición de medios independientes asociados a una sociedad civil fuerte, con un empresariado autónomo del poder político; el caso más emblemático de este patrón sería el de Nuevo León (Smith, et al., 2008).

Sin embargo, en este último grupo de estados que gozan de un espacio público con voces diversas también podrían incluirse aquellos estados que tienen medios muy importantes con posturas ideológicas antagónicas.

Es decir, en algunos estados se han instalado medios que no se integran a la gran tradición de periodismo independiente y apartidista, con un gran compromiso social. Esto es, estados en los que se han desarrollado medios que representan a grupos de diferentes corrientes ideológicas, incluso medios que llegan a tener un signo partidista, pero como coexisten diversos medios importantes de diferentes posturas ideológicas, esto lleva a que el espacio público tenga una diversidad de voces.

Finalmente, este espacio público sí refleja una mayor diversidad de posturas políticas de la sociedad. El estado de Yucatán podría ser el caso emblemático de este grupo. En esta entidad suelen coexistir medios importantes asociados al PAN y medios importantes asociados al PRI. Esta diversidad de voces permite que el espacio público no esté 
cooptado por un solo agente, como podría ser el gobernador (Berlín, 2007).

Para matizar esta clasificación, hay que insistir en que las relaciones de poder, como diría Foucault, son inestables. Es decir, el control o independencia de los medios es variable en el tiempo y depende de muchos factores, entre ellos: 1) el carácter más o menos autoritario del gobernador en turno; 2) el nivel de madurez política y económica de la sociedad civil local; 3) el profesionalismo de los medios (por ejemplo, los más independientes y serios saben comercializar sus páginas con las empresas de la iniciativa privada para no depender del gobernador en turno); 4) la competitividad electoral, es decir, la larga permanencia de un partido en el poder o la continua alternancia de partidos en la gubernatura.

Todos estos factores motivan muchos cambios en la relación del gobernador con los medios locales, de manera que en ocasiones hay una larga historia de sumisión de los medios, como sucedía en Oaxaca, caso que cambió en 2010 cuando, después de setenta años de dominio priista, finalmente se produjo una alternancia (Ruelas y Dupuy, 2013).

En otros estados, los principales medios representan a diferentes sectores partidistas e ideológicos y esto, normalmente, produce un espacio público con voces diversas, como tradicionalmente sucede en Yucatán. Sin embargo, en ocasiones toma el cargo un gobernador carismático que logra concitar la simpatía de casi todos los medios importantes de la entidad, incluso de los medios antagónicos a la ideología del gobernador; esto ha pasado también en Yucatán (Berlín, 2007).

Otra circunstancia decisiva en las primeras décadas del siglo XXI fue la llamada "guerra contra el narcotráfico". En esta época se pudieron observar estados del norte y centro del país secuestrados por las mafias del narcotráfico, como Coahuila, Tamaulipas, Durango y Michoacán (Del Palacio, 
2015). En estos estados, los periodistas tuvieron que rendir sus plumas ante las mafias y el Gobierno local toleró este juego perverso, incluso quizá lo aprovechó para manipular a los periodistas (Del Palacio, 2015).

\section{Conclusiones}

En este artículo se han citado reportes de investigación de todo el país que muestran cómo los gobernadores han acumulado poder durante la transición, y que con ello, aparentemente, se habrían fortalecido los autoritarismos locales.

A pesar de que en el estado de Querétaro los gobernadores se vuelven muy dominantes y controlan al resto de los poderes e instituciones públicas, se cree que en este caso sí se puede hablar de una democracia porque hay elecciones libres y competitivas; también existe un clima de respeto a los derechos civiles.

Gracias a todo esto, en los últimos veinte años se han registrado gobiernos de alternancia tanto del PAN como del PRI. En Querétaro hay una democracia, aunque se registran graves transgresiones a este tipo de régimen, por ejemplo, en esta entidad no se puede hablar de una poliarquía, y el espacio público suele ser controlado férreamente por el gobernador en turno.

En el tema del control de medios que ejerce el gobernador, Querétaro parece ser un claro ejemplo de lo que sucede en la mayor parte de los estados del país. Los diversos reportes sobre los estados de la república muestran que los gobernadores suelen cooptar a los medios para integrarlos a su estrategia comunicacional (Hernández y Hernández, 2011; Santillán Buelna, 2007; Orozco Murillo, 2007; Ortega Polanco, 2013; Del Palacio, 2015; González, 2015; Gutiérrez, 2013; Lemini, 2015; Rodelo, 2008; Ruelas y Dupuy, 2013). 
Muchos de estos reportes también advierten que el control de medios es un ejemplo de cómo los gobernadores controlan a los poderes públicos y a la sociedad civil de sus estados. Con estrategias clientelares, o incluso con la represión de diversos actores públicos, los gobernadores pueden ejercer el poder sin ningún contrapeso en sus respectivas entidades (Campos, 2012; Ruelas y Dupuy, 2013; Hernández, 2013; Espino y Mendoza, 2015).

Los autores que escriben sobre este tema aseguran que el renovado poder de los gobernadores les permite, incluso, desarrollar una influencia decisiva en la política nacional (Campos, 2012; Hernández, 2008; Hernández, 2013). Los gobernadores controlan las elecciones locales, nominan a los candidatos de sus partidos y los llevan a triunfar; cuando estos lleguen al Congreso de la Unión, los legisladores nacionales responderán en gran medida a los intereses de su protector. Aparte, se debe mencionar a la Conago, la cual obliga al presidente de la república a negociar las políticas que afectan a los estados.

Este ampliado poder de los gobernadores es uno de los nuevos rasgos del sistema político mexicano que ha emergido de la transición política. Hasta donde muestran los reportes de investigación, los gobernadores han logrado contener en muchas ocasiones el poder de los presidentes de la república (Hernández, 2009a; Martínez, 2013). Desgraciadamente, este papel de los gobernadores no ha abonado en una democracia más íntegra; por el contrario, quizá, los excesos de los gobernadores forman parte de las numerosas disfunciones del nuevo sistema político mexicano.

Los gobernadores en las últimas décadas fueron librándose de todos los controles, al grado de que actualmente ya no pueden ser removidos por el presidente de la república ni por el Congreso de la Unión ni por la Suprema Corte (Hernández, 2008). Si un presidente de la república desea remover a un gobernador, pero este se resiste, el gobernador se 
mantendrá, como sucedió en los casos de Roberto Madrazo, Mario Marín y Ulises Ruiz, entre otros (Hernández, 2009a).

Hay muchos casos que muestran que nadie puede llamar a cuentas a los gobernadores, y esto propicia vicios innumerables en las administraciones estatales (Martínez, 2013; Hernández, 2013; Casar, 2015). Entre los peores se pueden citar la opacidad en el manejo de los recursos; el endeudamiento de los estados (caso Humberto Moreira, en Coauhila); el enriquecimiento ilícito de los gobernadores y de su círculo de amigos y familiares (caso Andrés Granier, en Tabasco, y Luis Armando Reinoso, en Aguascalientes); las violaciones impunes a los derechos humanos (caso Mario Marín, en Puebla, y Ulises Ruiz, en Oaxaca), etc.

Además existen entidades donde las elecciones son férreamente controladas por una clase política y, gracias a ello, cuentan con una historia de más de ochenta y cinco años con un solo partido en el poder, pero también existen otras entidades donde la alternancia es frecuente y obliga a los gobernadores a intentar un buen gobierno.

Nuevamente, el problema es que, al no tener contrapesos, los gobernadores pueden llegar a los excesos que han sido tan denunciados en el nivel nacional. Por eso, aun en los estados donde se registran diversos procesos de alternancia y de competitividad electoral, se llegan a verificar graves problemas de corrupción atribuida al gobernador (Martínez, 2013; Hernández, 2013; Casar, 2015).

Todo esto lleva a pensar que la única solución de fondo sería el promover, desde el nivel nacional, un sistema de rendición de cuentas para los gobernadores, tanto en lo económico como en lo social y en lo político, de manera que los excesos sean castigados incluso con su destitución. A este respecto, Sartori (1994) asegura que sólo cuando los políticos están obligados a rendir cuentas y pagar por sus acciones, y sólo entonces, actuarán cumpliendo los estándares democráticos a los que se comprometieron. 
Bibliografía

Academia Mexicana de Derechos Humanos (1994). Las elecciones federales en México según seis noticiarios de televisión. México: Alianza Cívica/Academia Mexicana de Derechos Humanos.

- (2000). Las elecciones federales de 2000 en México. Análisis cualitativo de la cobertura y gastos de campaña en T. v. México: Alianza Cívica/Academia Mexicana de Derechos Humanos.

Ackerman, J. M. (20I5). El mito de la transición democrática. Nuevas coordenadas para la transformación del régimen mexicano. México: Ediciones Temas de Hoy.

Aguayo, S. (2014). El México de la sociedad organizada, los poderes fácticos y Enrique Peña Nieto. México: Editorial Ink. Ebook.

Balán, P. E. (20I3). “Autoritarismo subnacional: clasificación, causas, teoría" (ponencia presentada en las VII Jornadas de Jóvenes Investigadores, Instituto de Investigaciones Gino Germani, 6, 7 y 8 de noviembre de 2013). Universidad Torcuato Di Tella: Buenos Aires.

Barrio del Castillo, I., González Jiménez, J., Padín Moreno, L., Peral Sánchez, P., et al. (2006). El estudio de caso. Métodos de investigación educativa. Madrid: Universidad Autónoma de Madrid.

Berlín, I. G. (2007). Comunicación gubernamental en los espacios locales. Estudio de caso: el ayuntamiento de Mérida, Yucatán, México, durante el periodo (200l-2004) (tesis doctoral inédita). Universidad de La Laguna: Tenerife.

Campos, S. A. (2012). "Paradojas de la transición democrática: autoritarismo subnacional en México”. Estudios Políticos, (27), 2 I-45.

Casar, M. A. (20I0). Sistema político mexicano. Oxford University Press: México.

(20I5). México, anatomía de la corrupción. México: CIDE-IMCO. Recuperado de: http://imco.org.mx/wp- 
content/uploads/20I5/05/20I5_Libro_completo_AnaBibliografía tomia_corrupcion.pdf

Córdova, A. (1972). La formación del poder político en México. México: Ediciones Era.

Cueto, A., y Espinosa, J. (2003). "La prensa brindó más espacios al PRI durante el periodo electoral”. Tribuna de Querétaro, (249), p. 10.

Del Palacio, Celia (coord.) (2015). Violencia y periodismo regional en México. México: Juan Pablos.

Diamond, L., y Morlino, L. (2005). Assessing the Quality of Democracy. Baltimore: The Johns Hopkins University Press.

Espino, G. (2003). El crack del 97, ¿por qué los queretanos promovieron el vuelco electoral más importante de su historia? Querétaro: UAQ-IEQ-INAH.

(20I2). "El voto independiente domina el escenario electoral de Querétaro”, en M. G. Morales Garza, y G. Espino Sánchez (auts.), Querétaro: democracia a dos bandas (Pp. I0I-I58). Querétaro: Universidad Autónoma de Querétaro.

(I 3 de julio de 20 I3a). Entrevista personal a periodista I. Querétaro, México.

( 13 de agosto de 20/3b). Entrevista personal a periodista 2. Querétaro, México.

(09 de junio de 2014a). Entrevista personal a periodista 6. Querétaro, México.

(I3 de junio de 20 I4b). Entrevista personal a político I. Querétaro, México.

- y Mendoza, E. (20I5). Los gobernadores, enclaves del autoritarismo en México, Sometimiento y subordinación de los medios locales. México: Fontamara.

Espinosa, J. (2003). "La información de los medios, una mercancía al mejor postor”. Tribuna de Querétaro, (239), pp. 3-4. 
Bibliografía
Fortanell, B., y Cabrera, J. (2009). "290 millones de pesos recibieron televisoras”. Tribuna de Querétaro, XII(520), p.II.

García, C. (20I2). "El jugoso negocio de Televisa: cancelan Espacio 2012 en Oaxaca”. Revista Mexicana de Comunicación. Recuperado de: http://mexicanadecomunicacion. com.mx/rmc/20I2/I0/29/el-jugoso-negocio-de-televisacancelan-espacio-20I2-en-oaxaca/

Gibson, E. L. (2006). “Autoritarismo subnacional: estrategias territoriales de control político en regímenes democráticos". Desafios, 14, 204-237.

Grant, W. (1995). Insider groups, outsider groups and interest group strategies in Britain. Londres: Harvester Wheatsheaf, Political Science.

González, P. (1976). La democracia en México. México: Ediciones Era.

González, R. (20I5). "Economically-driven partisanshipOfficial Advertising and Political coverage in Mexico: The Case of Morelia". Journal of Latin American Communication Research, 5(I), 3-36. Recuperado de: http://alaic. org/journal/index.php/jlacr/article/view/78

González, J. M., y Quesada, F. (1988). Las teorías de la democracia. Barcelona: Editorial Anthropos.

Gutiérrez, P. C. (20I3). El poder de los gobernadores en México 200 I-2012: límites institucionales y políticos a nivel subnacional (tesis de doctorado inédita). FLACSO: México.

Hallin, D. C., y Mancini, P. (2008). Sistemas mediáticos comparados. Barcelona: Hacer Editorial.

Hernández, R. (2008). El centro dividido. La nueva autonomía de los gobernadores. México: El Colegio de México.

Hernández, E. (2009a). "Presidencialismo y gobiernos estatales: partidos, elecciones y federalismo", en $\mathrm{M}$. Alcántara, y E. Hernández Norzagaray (eds.), México, el 
nuevo escenario político ante el bicentenario (pp. |8|-2|0). España: Ediciones Universidad de Salamanca.

Hernández, H. (2009b). "No tuvimos para pagar cobertura periodística”. Tribuna de Querétaro, (497), p. 8.

Hernández, M. E. (20I0). "Franquicias periodísticas y sinergias productivas en la prensa mexicana: en busca de nuevos modelos de financiamiento", en M. E. Hernández Ramírez (coord.), Estudios sobre periodismo. Marcos de interpretación para el contexto mexicano (pp. 55-I2I). Guadalajara: Universidad de Guadalajara.

Hernández, J. L. (20I3). "El regreso del PRI: ¿ante qué debemos estar preparados?". Análisis Plural, (segundo semestre de 2012), I09-126.

Hernández, A., y Hernández, J. (20II). Las elecciones 2010 en Hidalgo y la cobertura de medios en el proceso electoral. México: Mimeo.

Hughes, S. (2006). Redacciones en conflicto. El periodismo y la democratización en México. México: Miguel Ángel Porrúa. IFE (2012). Estadísticas y resultados electorales. Recuperado de: http://www.ine.mx/archivos3/portal/historico/contenido/Historico_de_Resultados_Electorales/

Lawson, C. H. (2002). Building the fourth state: democratization and the rise of a free press in Mexico. Berkeley: University of California Press.

Lazos, F. (1997). "El voto de la prensa" (en el ciclo de conferencias ¿Qué pasó el 6 de julio?, realizadas del 8 al 9 de septiembre de 1997). Museo Regional de Querétaro: Querétaro, México.

Lemini, J. L. (20I5). "Periodismo en Coahuila, entre la violencia y el deber ser", en C. del Palacio Montiel (coord.), Violencia y periodismo regional en México (pp. I7I-202). México: Juan Pablos.

Linz, J. J. (2009). Sistemas totalitarios y regímenes autoritarios. Madrid: Centro de Estudios Políticos y Constitucionales. 
Bibliografía

Loaeza, S. (20I0). "La metamorfosis del Estado: del jacobinismo centralizador a la fragmentación democrática", en S. Loaeza, y J. Prud'homme (coords.), Instituciones y procesos políticos (pp. 23-70). México: El Colegio de México.

Maloney, W., Jordan, G., y Mc Lauchlin, A. (1994). 'Intermodel Revisited". Journal of Public Policy, 14, 17-38.

Márquez Ramírez, M. (20I2). "Valores normativos y prácticas de reporteo en tensión: percepciones profesionales de periodistas en México". Cuadernos de Información, (30), 97-II0.

Martínez, P. C. (2006). "El método de estudio de caso. Estrategia metodológica de la investigación científica”. Pensamiento y gestión, (20), 165-193.

Martínez, M. (I0 de noviembre de 20I3). "Resisten reformas los gobernadores". Reforma, p. I.

Meyer, L. (1995). Liberalismo autoritario. Océano: México.

Morales, M. G. (2012). Querétaro: democracia a dos bandas. Querétaro: Universidad Autónoma de Querétaro.

O'Donnell, G., y Schmitter, P. C. (1994). Transiciones desde un gobierno autoritario 4. Conclusiones tentativas sobre las democracias inciertas. Barcelona: Paidós.

Orozco Murillo, R. (2007). Relaciones prensa-gobierno en Tepic: hacia la caracterización de prácticas predominantes en el periodismo local de México (tesis de maestría inédita). Universidad de Guadalajara: Guadalajara.

Ortega Polanco, L. G. (20I3). "Prensa y poder político en Xalapa. Proceso electoral 2010". Derecho a comunicar, (7), I-33.

Riva Palacio, R. (2004). La prensa de los jardines. Fortalezas y debilidades de los medios en México. México: Plaza Janes.

Ruelas, A. C., y Dupuy, J. (20I3). "El costo de la legitimidad. El uso de la publicidad oficial en las entidades federativas". Fundar, (19), 9-100. 
Rodelo Amezcua, F. V. (2008). Ejercicio de la libertad de Bibliografía prensa y sus limitaciones en entornos violentos. El caso de los periodistas de Culiacán, Sinaloa, México (tesis de maestría inédita). Universidad de Guadalajara: Guadalajara.

Rodríguez, A., Espinosa Trujillo, N., y Arteaga Pérez, J. F. (20l0). La cobertura de los medios a las campañas para la gubernatura de Querétaro en 2009 (tesis de licenciatura inédita). Universidad Autónoma de Querétaro: Querétaro.

Santillán Buelna, J. R. (2007). "Teatralización política y periodística. Análisis periodístico de la elección interna del PRI para elegir su candidato a la gubernatura mexiquense". Andamios. Revista de Investigación Social, 4(7), 227-247.

Síntesis Informativa del Bajío (1997). Análisis de contenido de la cobertura que brindó la prensa local a los partidos políticos y candidatos durante el proceso electoral de 1997. Querétaro: Mimeo.

Smith, C., García Vázquez, N. J., y Pérez Esparza, J. D. (2008). "Análisis de la ideología empresarial regiomontana. Un acercamiento a partir del periódico El Norte”. CONfines relaciones internacionales y ciencia política, 4(7), II-25.

Stake, R. E. (2005). Investigación con estudios de caso. Madrid: Ediciones Morata.

Sartori, G. (1987). Partidos y sistemas de partido. España: Editorial Alianza.

- (1993). ¿Qué es la democracia? México: Nueva Imagen.

(1994). Ingeniería constitucional comparada. Chile: Fondo de Cultura Económica.

Secretaría de Gobernación (20I2). Encuesta Nacional de Cultura Política y Prácticas Ciudadanas. México: Secretaría de Gobernación. Recuperado de: http://www.encup. gob.mx/

Trejo, R. (200I). Mediocracia sin mediaciones. Prensa, televisión y elecciones. México: Ediciones Cal y Arena. 
Bibliografía Villamil, J. (2009). Si yo fuera presidente, el reality show de Peña Nieto. México: Grijalbo.

Weldon, J. (1997). "The Political Sources of Presidencialismo in Mexico”, en S. Mainwaring, y M. Shugart (eds.), Presidentialism and Democracy in Latin America (pp. 225-258). Nueva York: Cambridge University Press.

Woldemberg, J. (2002). La construcción de la democracia. Plaza y Janés: México. 